Dinamika Sosial Budaya, Vol 22, No. 2, Desember 2020, pp 158-164

p-ISSN: 1410-9859\& e-ISSN: 2580-8524

http://journals.usm.ac.id/index.php/jdsb

\title{
NILAI KEARIFAN LOKAL DALAM RUMAH ADAT LIMBUNGAN SUKU SASAK
}

\section{Firda Devianti Komalasari, Hamdani, Hulaemi Umar, Irma Suryani, Juliana, Juliani, Nursaptini, Muhammad Tahir}

Pendidikan Guru Sekolah Dasar, Universitas Mataram, Indonesia

DOI: http://dx.doi.org/10.26623/ jdsb.v21i2.1698

\begin{abstract}
Abstrak
Penelitian ini bertujuan untuk mengenalkan nilai yang terkandung pada setiap pola artsitektur rumah adat Limbungan Desa Perigi Kecamatan Suela Kabupaten Lombok Timur. Penelitian ini meupakan penelitian deskriptif menggunakan pendekatan kualitatif. Pengumpulan data dilakukan melalui metode observasi, wawancara, dan dokumentasi. Hasil penelitian ini menjukkan bahwa, (1) Rumah adat limbungan ini terbuat dari bahan-bahan alami yang masih mudah didapatkan seperti: kayu, daun ilalang, bambu, dan getah pohon, (2) Rumah adat limbungan ini terdiri dari komponen-komponen dan memiliki ciri khas masing-masing, diantaranya terdiri dari atap, pondasi, dinding, pintu, jendela, tangga, lantai/teras, (3) Nilai atau makna dari setiap komponen rumah adat ini meliputi : nilai tata karma, kepedulian sosial, kepercayaan, sedangkan pada atap yang semakin menjorok ke bawah menunjukan rasa hormat, dinding rumah adat ini mengandung nilai kesederhanaan yang dapat diterapkan dalam kehidupan, dan untuk pintu dimasing-masing rumah adat ini serentak menghadap utara dikarenakan matahari terbit dari utara sehingga sinar dari matahari yang mengandung vitamin D yang baik untuk pembentukan tulang
\end{abstract}

This study aims to introduce the value contained in each architectural pattern of the Limbungan traditional house, Perigi Village, Suela District, East Lombok Regency. This research is a descriptive study using a qualitative approach. Data collection was carried out through observation, interview and documentation methods. The results of this study show that, (1) The limbungan traditional house is made of natural materials that are still easily available, such as: wood, thatch leaves, bamboo, and tree sap, (2) This limbungan traditional house consists of components and has the characteristics of each, including consisting of roofs, foundations, walls, doors, windows, stairs, floors / terraces, (3) The value or meaning of each component of this traditional house includes: karmic values, social care, belief, while in The roof that juts down shows respect, the walls of this traditional house contain a value of simplicity that can be applied in life, and for the doors in each of these traditional houses simultaneously face north because the sun rises from the north so that the rays from the sun contain good vitamin D for bone formation Keywords: Local Wisdom, Limbungan Traditional House 
Dinamika Sosial Budaya, Vol 22, No. 2, Desember 2020, pp 158-164

p-ISSN: 1410-9859\& e-ISSN: 2580-8524

http://journals.usm.ac.id/index.php/jdsb

\section{PENDAHULUAN}

Indonesia merupakan negara kepulauan yang didiami oleh beranekaragam suku bangsa (Rohmi: 2017). Dari hal tersebut dapat kita ketahui bahwa Indonesia adalah Negara yang kaya akan suku bangsa, di setiap provisi maupun daerah memiliki suku tersendiri. Provinsi Nusa Tenggara Barat misalnya dimana suku asli provinsi ini didiami oleh suku Sasak, Samawa dan Mbojo. Setiap suku tersebut memiliki ciri khas budaya masing-masing baik itu bahasa, adat istiadat, bagunan tradisional maupun kesenian tradisional. Hal tersebut sejalan dengan pendapat Sari (2013) yang mengatakan bahwa setiap suku bangsa memiliki ciri khas masing-masing yang membedakannya dengan suku lain. Ciri khas inilah yang akan membentuk identitas suatu suku bangsa. Pada tulisan kali ini penulis hanya akan berfokus pada nilai kearifan lokal salah satu bangunan tradisional suku Sasak yaitu rumah adat Limbungan yang terletak di dusun Perigi, Lombok Timur. Hal ini dikarenakan makna atau nilai yang terkandung pada bangunan rumah adat limbungan sangat penting untuk diketahui agar masyarakat semakin sadar dan lebih perduli terhadap budaya yang dimiliki, sehingga rumah adat limbungan ini tetap dilestarikan sebagai warisan budaya.

Sebagai salah satu warisan budaya, nilai-nilai kearifan lokal rumah adat limbungan ini keberadaanya harus tetap dipertahankan dan dijadikan sebagai salah satu strategi masyarakat lokal untuk memenuhi kebutuhan mereka. Alfian (2013:428) mengatakan bahwa kearifan lokal dapat diartikan sebagai pandangan hidup dan pengetahuan serta sebagai strategi kehidupan yang berwujud aktifitas yang dilakukan oleh masyarakat lokal dalam memenuhi kebutuhan mereka.
Rumah adat limbungan yang terletak di desa Perigi, Kabupaten Lombok Timur ini terdiri dari dua lingkungan yaitu Limbungan Barat dan Limbungan Timur, akan tetapi induknya berada pada Limbungan Barat. Adapun posisi bangunan rumah adat ini harus sama karena merupakan sebuah tradisi turun temurun, yang menjadi warisan budaya yang kaya akan nilai sejarah. Lebih lanjut, Rina Sabrina dkk. (2010) mengemukakan bahwa gaya arsitektur tradisional yang terdapat di Dusun Limbungan merupakan salah satu bentuk pusaka budaya yang kaya akan nilai sejarah, filosofi, seni, dan budaya masyarakat setempat. Selain itu, setiap arsitekstur pembangunan juga memiliki makna masingmasing. Pola arsitektur pembangunan rumah adat ini dibuat berdasarkan kepercayaan penduduknya dan sarat akan nilai budaya, misalnya jumlah tangga yang terdiri dari 3 atau 5 undakan yang mengandung makna bahwa 5 ini menunjukkan jumlah waktu shalat dan jumlah rukun Islam (Sukardi:2020). Untuk itu rumah adat ini perlu diberikan perhatian khusus sehingga makna-makna yang ada pada rumah ini tidak menghilang tergeser oleh arus globalisasi.

Pengambilan topik bangunan tradisional Sasak yaitu rumah adat Limbungan ini dilatarbelakangi oleh nilainilai budaya yang masih tetap terjaga akan tetapi masih kurang dikenal oleh masyarakat luas sehingga dapat di eksplorasi lebih jauh. Berdasarkan hasil studi pendahuluan dan wawancara dengan pemangku adat, rumah adat ini hampir punah dikarenakan kurangnya dana untuk perbaikan atau renovasi. jadi, tujuan dari penulisan ini yaitu untuk mengenalkan nilai yang terkandung pada setiap pola artsitektur rumah adat Limbungan, dusun Perigi, desa Limbungan, Kecamatan Suela, Kabupaten Lombok Timur. 
Dinamika Sosial Budaya, Vol 22, No. 2, Desember 2020, pp 158-164

p-ISSN: 1410-9859\& e-ISSN: 2580-8524

http://journals.usm.ac.id/index.php/jdsb

\section{METODE}

Metode yang digunakan dalam penelitian ini yaitu pendekatan kualitatif. data yang dikumpulkan berupa kalimat dan gambar. Penelitian ini berlokasi di pedesaan yang terletak di Dusun Limbungan, Desa Perigi, Kecamatan Suela, Kabupaten Lombok Timur, Nusa Tenggara Barat. Sumber data dari penelitian ini adalah data primer, dimana sumber data primer dalam penelitian ini diperoleh dari 3 responden yaitu: pemangku adat, warga, dan tokoh pemuda.Peneliti menggunakan metode pengumpulan data berupa observasi, wawancara/Interview, dan dokumentasi.Instrument penelitian ini adalah peneliti sendiri, peneliti menggunakan alat tulis untuk mencatat seputar hasil wawancara dan kamera untuk merekam dan membantu memperoleh data secara lengkap terkait rumah adat Suku Sasak Limbungan. Analisis data dilakukan dengan pengumpulan data, reduksi data, penyajian data dan mengambil kesimpulan, data-data hasil wawancara, observasi dan dokumentasi dikumpulkan kemudian disederhanakan, diringkas dalam konsep, kategori, kegiatan penyajian data dilakukan dengan menyusun sekumpulan informasi tentang rumah adat limbungan dalam bentuk catatan berupa teks naratif kemudian diambil kesimpulan.

\section{HASIL DAN PEMBAHASAN}

Salah satu rumah adat suku sasak yang berada di Lombok adalah rumah adat limbungan, masyarakat suku sasak menyebutnya dengan istilah bale yang berarti tempat berteduh. Nama rumah adat ini diambil dari kata Lumbung yakni sebuah tempat untuk meyimpan padi oleh masyarakat sasak limbungan, pada umumnya rumah adat limbungan sangat berbeda dengan rumah tempat tinggal baik bentuk maupun bahan yang digunakan untuk membuatnya.hal ini sejalan dengan penelitian yang telah dilakukan oleh Rohmi Wir'aeni pada tahun 2016 bahwa rumah adat memiliki arsitektur dan tata ruang yang berbeda dengan rumah tempat tinggal biasa pada umumnya karena terkait dengan lokasi pembangunan rumah di atas perbukitan dan aturan-aturan adat yang berlaku identik dengan tingkah laku masyarakat yang terbentuk akibat pengaruh lingkuna. Rumah adat ini terletak di desa perigi kecamatan suela kabupaten Lombok Timur, Nusa tenggara barat, keberadaan rumah adat ini tidak diketahui pasti tahun berapa mulai didirikan, namun penduduk sekitar meyakini keberadaan rumah adat ini sudah lama yang merupakan warisan dari nenek moyang mereka, rumah adat limbungan ini merupakan salah satu rumah yang masih mempertahankan bentuk asli dari rumah suku sasak yang ada dilombok sehingga tetap dilestarikan oleh masyarakat dan pemerintah setempat, jumlah penduduk yang mendiami kampung adat ini mengalami pertambahan sehingga pada masa pemerintahan Bupati Lombok timur (Ali bin dahlan) tahun 2013 dusun ini mengalami pemekaran, terbagi menjadi dusun limbungan barat dan dusun limbungan timur, dusun limbungan barat dan timur ini merupakan satu kesatuan dengan satu pemimpin adat, pusat/induk dusun ini tetap berada di dusun limbungan barat, jumlah penduduk yang mendiami rumah adat ini tidak diketahui pasti jumlah secara keseluruhan namun berdasarkan hasil wawancara pada hari minggu, 8 November 2020 terhadap pemangku adat (Papuk Meri) dengan merujuk pada data pemilihan umum jumlah penduduk di daerah limbungan barat 
sebanyak 285 kepala keluarga, $99 \%$ mayoritas penduduknya sebagai petani, $1 \%$ lainnya sebagai buruh dan ada yang marantau ke Malaysia menjadi TKI.
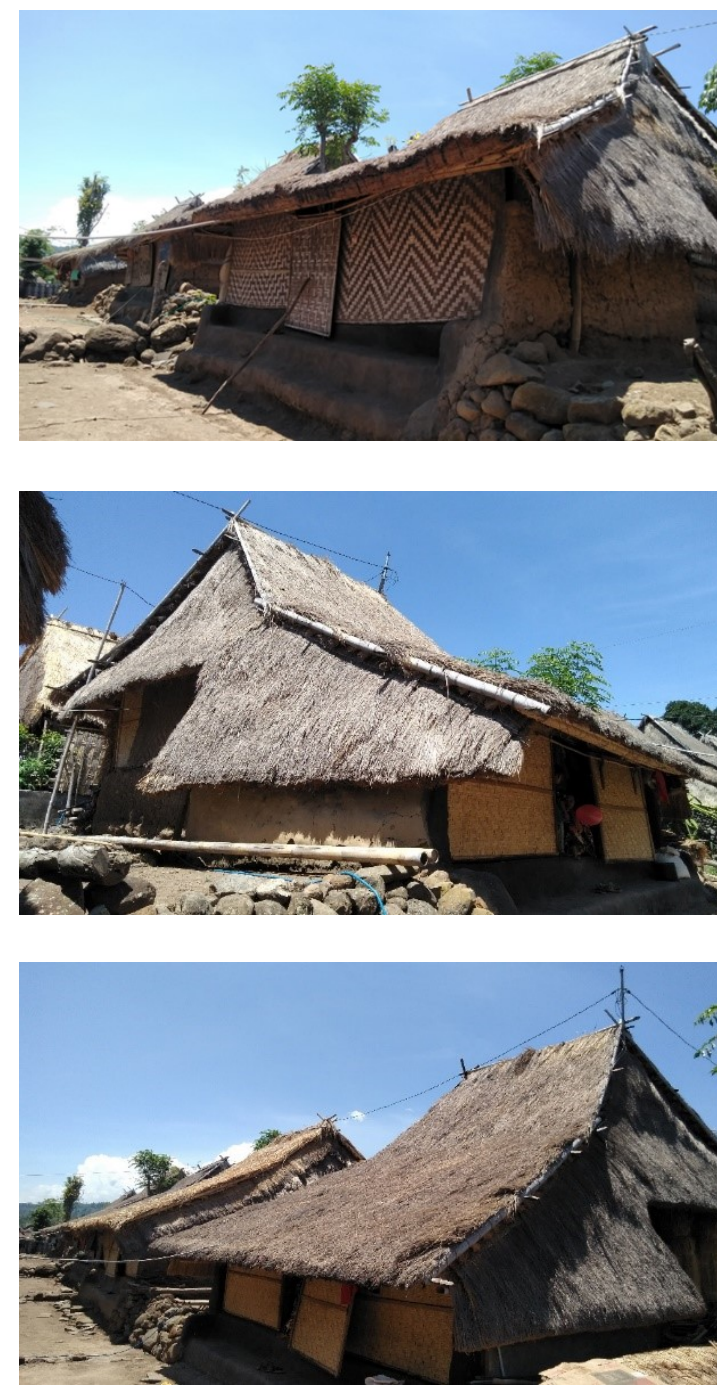

\section{Gambar Rumah Adat Limbungan (Sumber data: Dokumentasi peneliti)}

Rumah adat limbungan ini terbuat dari bahan-bahan alami yang masih mudah didapatkan yaitu: kayu, daun ilalang, bambu, dan getah pohon banten. Awalnya rumah adat ini hampir punah karena ketersediaan bahanbahan di alam sudah terbatas namun karena ada bantuan dana dari pemerintah untuk rumah adat, sehingga masih tetap ada sampai sekarang. Setiap rumah di desa adat limbungan memiliki bentuk dan komponen yang sama, jika ada masyarakat yang ingin membangun rumah dilingkungan rumah adat ini maka harus mengikuti bentuk yang sudah ada, jika ada yang mau membuat dengan bentuk yang berbeda, tidak diizinkan untuk tinggal disekitar lingkungan rumah adat. Sama halnya dengan rumah adat pada umumnya, rumah adat limbungan ini terdiri dari komponen-komponen dengan ciri khas masing-masing, diantaranya terdiri dari atap, ruangan, dinding, pintu, lantai/teras, jendela, tangga.

1. Atap, atap bale sasak ini berbentuk limas yang terbuat dari daun ilalang dan bambu yang mudah didapatkan dilingkungan sekitar, berdasarkan hasil pengamatan jika dilihat dari luar atapnya lebih besar dari pada badan rumah, bentuk atap bagian depan lebih menjorok kebawah hal ini memiliki makna bahwa sikap sopan santun ketika masuk kedalam rumah posisi badan menunduk yang menunjukkan rasa hormat.

2. Dinding, pada bagian depan dan belakang terbuat dari anyaman bambu, tiang-tiang rumah tempat melekatnya dinding menggunakan bambu dan di bagian bantalan juga menggunakan bambu, untuk mengikat dinding dengan tiangnya digunakan rotan, bahan-bahan yang digunakan membuat dinding ini sederhana, mudah didapat seperti tanah dan bambu kemudian masyarakat sendiri yang mengolahhya hingga menjadi dinding, proses pemasangan anyaman 
dinding bambu dilakukan dengan sederhana yaitu diikat pada tiang. Yang menunjukkan kesederhanaan masyarakat limbungan dalam hal dapat memamfaatkan bahan-bahan sederhana yang sudah tersedia dialam, mudah didapatkan, hal ini mengandung nilai kehidupan bahwa kesederhanaan dapat diterapkan dalam kehidupan.

3. Pintu/lawang, terdapat beberapa pintu yaitu: pintu disetiap kamar dan diteras, pintu diteras terletak didepan sebagai jalan keluar masuk, pintu disetiap kamar terletak ditengahtengah sebagai penghubung antara kamar dengan teras. Setiap pintu dimasing-masing rumah adat ini serentak menghadap utara hal ini karena matahari terbit dari utara sehingga sinar dari matahari yang mengandung vitamin D baik untuk pembentukan tulang dapat masuk kedalam rumah, pintu rumah dibuat dengan posisi rendah hal ini karena ketika masuk ke dalam posisi badan menunduk yang mencerminkan sikap saling menghargai dan menghormati antara tamu dan tuan rumah. Untuk mengunci pintu rumah digunakan tongkat kayu atau bambu sebagai pengunci jika akan bepergian hal ini mengandung nilai kepercayaan terhadap sesama masyarakat.

4. Lantai/teras, terbuat dari campuran tanah, getah pohon banten, air, kemudian jika sudah kering dicat/diolesi dengan 10 batrai yang diambail bagian hitamnya, hasil cat dengan batrai ini mampu bertahan 23 tahun walaupun duduk dengan pakaian putih tidak akan menempel,pada saat musim hujan juga tidak akan luntur/rusak setelah 2-
3 tahun akan dicat kembali dengan bahan-bahan yang sama.

5. Jendela, rumah adat ini tidak memiliki jendela, pada siang hari di dalam rumah akan tetap gelap karena tidak ada jendela sebagai celah matahari untuk masuk ke dalam rumah. Cahaya dari sinar matahari masuk melalui pintu, teras dan celahcelah dinding yang terbuat dari anyaman bambu. Rumah adat ini tidak mempunyai jendela disebabkan oleh beberapa kemungkinan, salah satunya berdasarkan letak rumah adat Sasak Limbungan ini terletak diarea perbukitan kaki gunung Rinjani dengan hawa dingin.sehingga untuk menghindari udara dingin tidak dibuatkan jendela pada rumah.

6. Tangga, terbuat dari bahan-bahan yang sama seperti pembuatan teras, terdapat 2 tangga diluar dan dalam rumah, diluar rumah terdapat 2 anak tangga berbentuk memanjang dipergunkan oleh masyarakat sebagai tempat duduk saat beristirahat, bertegur sapa dengan tetangga sekitar, di dalam terdapat anak tangga berjumlah 3,5 , jarang yang berjumlah 4 berfungsi sebagai penghubung antar ruang, masyarakat sasak limbungan meyakini jumlah anak tangga 5 mencerminkan jumlah waktu sholat dan jumlah rukun iman. Hal ini tentunya memiliki makna jumlah anak tangga mencerminkan bahwa masyarakat suku sasak limbungan selalu menjalankan syariat islam seperti yang terkandung dalam rukun islam, setiap rumah memiliki tangga dengan bentuk, warna dan ukuran yang sama tidak ada yang menonjol, hal ini menunjukkan bahwa masyarakat limbungan memiliki 
sikap rendah hati, tidak angkuh dan tidak sombong.

7. Ruangan, terdiri dari ruang tidur, dapur, teras dan dibagian atas terdapat lumbung/pantek, ruang tidur digunakan untuk menyimpan barangbarang berharga dan tempat beraktifitas, tidur untuk anak prempuan dan istri, kamar tidur ini juga di gunakan jika ada anggota keluarga yang melahirkan maupun meninggal, mulai dari dimandikan hingga dibungkus dengan kain kafan akan ditempatkan di dalam kamar. Teras digunakan sebagai tempat untuk menerima tamu, ngobrolngobrol jika ada keluarga yang berkunjung, masing-masing ruangan dirumah ini memiliki fungsi ruangan kamar tidur untuk beraktivitasnya anak prempuan dan istri, ruangan teras sebagai ruangan umum untuk menerima tamu. Fungsi tiap ruangruang tersebut menujukkan batasanbatasan tamu ketika berada di dalam rumah. Hal tersebut mengajarkan tata krama pada masyarakat untuk menghargai pemilik rumah dan menjaga prilaku ketika bertamu, dibagian atas rumah tepatnya dibawah atap terdapat ruangan yang disebut lumbung, tempat ini digunakan untuk menyimpan padi hasil panen hal ini sebagai persiapan karena tidak setiap tahun hasil panen masyarakat berhasil. Jika panen gagal masyarakat masih mempunyai simpanan beras yang terdapat dilumbung.

\section{SIMPULAN}

Rumah adat limbungan yang bertempat di Desa Perigi, merupakan salah satu rumah adat yang masih dijaga keasliannya secara turun temurun,seiring perkembangan zaman kampung adat limbungan mengalami pemekaran menjadi dusun limbungan barat dan timur, induk/pusatnya tetap berada di limbungan barat, semua rumah adat didusun limbungan memiliki bentuk yang sama dengan komponen-komponen dan ciri khas masing-masing, bentuk rumah ini tidak dapat diubah jika ada masyarakat kampung adat yang ingin merubah bentuk dari rumah adat tersebut, terutama pada bagian atap dan letak pintu maka masyarakat tersebut harus keluar dari bagian anggota masyarakat kampung adat Limbungan. Mayoritas masyarakat bekerja sebagai petani.

\section{DAFTAR PUSTAKA}

Sugiyono. (2019). Metode Penelitian Kuantitatif,Kualitatif dan $R \& D$. Bandung: Alfabeta.

Arikunto, S. (2010). Prosedur Penelitian. Jakarta: PT.Rineka Cipta.

Wiraeni, Rohmi. "Nilai Edukatif pada Arsitektur Rumah Adat Bale Sasak di Dusun Limbungan Kabupaten Lombok Timur NTB." Jurnal Pendidikan Seni Rupa, 2016: 167-175.

Rina Sabrina, Antariksa, Gunawan Prayitno. "Pelestarian Pola Permukiman Tradisional Suku Dusun Limbungan Kabupaten Lombok Timur." Jurnal Tata Kota dan Daerah, 2010: 87-108.

Alfian, M. (2013). "Potensi Kearifan Lokal dalam Pembentukan Jati Diri dan Karakter Bangsa". Jurnal Pendidikan, 424435.

Sari, Y. R. (2013). "Peranan Gereja Batak Karo Protestan dalam Melestarikan 
Dinamika Sosial Budaya, Vol 22, No. 2, Desember 2020, pp 158-164

p-ISSN: 1410-9859\& e-ISSN: 2580-8524

http://journals.usm.ac.id/index.php/jdsb

dan Mempertahankan Kebudayaan Suku Batak Karo (StudiI Dikecamatan Medan Selayang)". Jurnal Pendidikan, 1.

Sabrina, Rina Dkk. 2010. "Pelestarian

Pemukiman Tradisional Suku Sasak DusuNLimbungan Kabupaten Lombok Timur". Jurnal Tata Kota Dan Daerah Oleh Fakultas Teknik Universitas Brawijaya, vol 1, no 2 .

Sukardi Interview. 2020. "Makna yang Terkandung Pada Rumah Adat Limbungan Kabupaten Lombok Timur NTB". Lombok Timur. 